\title{
Estado do conhecimento sobre jornada de trabalho docente no ensino fundamental e médio
}

\author{
Andreza Barbosa ${ }^{1}$
}

Renata Cristina Oliveira Barrichelo Cunha ${ }^{2}$

Verônica Martins ${ }^{3}$

\section{Resumo}

Esse artigo sistematiza o estado do conhecimento sobre jornada de trabalho docente evidenciando como a temática vem sendo discutida nas pesquisas. As análises foram organizadas em quatro eixos que abordam as relações da jornada de trabalho com: os salários, a especificidade desse trabalho, o gênero e a legislação. Considerando que a jornada de trabalho é uma das condições que mais influencia a qualidade do trabalho dos professores, é fundamental que os estudos que abordem temas relacionados ao trabalho docente considerem as condições que os professores têm para desenvolver seu trabalho. O caráter inventariante deste artigo pode contribuir com essas discussões.

Palavras-chave: Jornada de trabalho docente; Condições de trabalho docente; Políticas educacionais.

\section{The state of knowledge about teacher's workload in the elementary and high school}

\section{Abstract}

This paper establishes the state of knowledge about teacher's workload in order to emphasize how the theme has been discussed in researches. The work analysis is organized into four main aspects that deal with the relations of the workload with: the salaries, the specificity of this work, the gender and the legislation. Considering that workload is one of the conditions that most influence the quality of teachers' work, it is fundamental that studies about issues related to teaching work consider the teacher's work conditions. The inventorying character of this article may contribute to these discussions.

Keywords: Teacher's workload; Teacher's work conditions; educational politics.

\section{Introdução}

A argumentação desenvolvida ao longo do artigo parte do pressuposto de que o trabalho docente se constitui como tarefa ampla e complexa que extrapola os limites da sala de aula (OLIVEIRA, 2010). Há que se considerar, portanto, que ao contrário de outras profissões, o trabalho do professor costuma se estender para além do local de trabalho, adentrando o espaço

\footnotetext{
${ }^{1}$ Universidade Metodista de Piracicaba. Piracicaba/SP. Endereço eletrônico: andrezab27@gmail.com

${ }^{2}$ Centro Universitário Salesiano de São Paulo. Americana/SP. Endereço eletrônico: renata_bcunha@yahoo.com.br

${ }^{3}$ Universidade Metodista de Piracicaba. Piracicaba/SP. Endereço eletrônico: martins.veronica.94@gmail.com
} Periódico Horizontes - USF - Itatiba, SP-Brasil - e019012 
e o tempo privados.

Isto ocorre porque o trabalho realizado em sala de aula é precedido de várias horas de preparo de aulas, correção e elaboração de provas e atividades, realização de estudos voltados para as aulas ou para o aprimoramento profissional do professor, dentre outras atividades extraclasse que, recentemente, podem incluir ainda um amplo leque de tarefas burocráticas a serem desempenhadas com o auxílio das tecnologias da informação e comunicação, como inserção de notas em um sistema informatizado, preenchimento de formulários eletrônicos etc.

Embora as condições precárias de trabalho às quais os professores têm estado submetidos no Brasil possam induzir práticas improvisadas, a princípio, não é possível ir ao encontro dos alunos sem que a aula tenha sido minimamente preparada ou a prova elaborada ou corrigida. Nesse sentido, as atividades extraclasse que compõem a jornada de trabalho docente se caracterizam como atividades básicas para o desempenho do trabalho docente. Franchi $(1995$, p.27) destaca que o bom professor, isto é, aquele "[...] que conduz as experiências pedagógicas mais bem-sucedidas, consome nessas atividades extraclasse tempo igual, senão maior, do que o tempo das horas de aula em que se ocupa".

É preciso considerar que a jornada de trabalho dos professores, como apontado por Souza (2008), é dividida entre o tempo de ensino, caracterizado como o trabalho desempenhado com os alunos, em sala de aula, e o tempo de trabalho que, por sua vez, refere-se a todo o processo de trabalho do professor dentro e fora da sala de aula, englobando as atividades extraclasse e extrapolando o tempo da aula.

Como o tempo de trabalho é difícil de ser aferido, até porque costuma se misturar com o tempo privado, podemos considerar a complexidade que é termos uma dimensão da composição da jornada de trabalho dos professores que, de fato, se aproxime da realidade.

O estudo da jornada de trabalho dos professores, especificamente, é uma temática pouco compreendida que, apenas recentemente, vem sendo mais explorada. Sua importância reside no fato de que a jornada é uma condição de trabalho com sérias implicações para a qualidade do trabalho docente. Tendo isso em vista, a partir do contexto de um projeto mais amplo interessado na configuração da jornada de trabalho dos professores da rede pública estadual

$$
\text { Periódico Horizontes - USF - Itatiba, SP-Brasil - e019012 }
$$


paulista ${ }^{4}$, esse artigo tem como objetivo sistematizar o estado do conhecimento sobre a jornada de trabalho dos professores.

O estado de conhecimento, segundo Morosini e Fernandes (2014, p.155) é a “[...] identificação, registro, categorização que levem à reflexão e síntese sobre a produção científica de uma determinada área, em um determinado espaço de tempo" e pode reunir artigos de periódicos, teses, dissertações e livros sobre uma temática específica. Para as autoras os resultados do estado de conhecimento (ou estudos de revisão) favorecem a compreensão de aspectos da realidade e informam o que está sendo discutido na comunidade acadêmica.

Na mesma perspectiva, Vosgerau e Romanowski (2014) acrescentam que os estudos de revisão permitem a análise da configuração de uma determinada área, identificando perspectivas teóricas, metodológicas, tendências, lacunas. Esses estudos têm, como destacado por Ferreira (2002), um caráter inventariante e uma perspectiva descritiva.

Essa elaboração é fundamental tendo em vista que

[...] a construção da pesquisa não é um empreendimento isolado. É uma construção coletiva da comunidade científica, um processo continuado de busca, no qual cada nova investigação se insere, complementando ou contestando contribuições anteriormente dadas ao estudo do tema. A proposição adequada de um problema de pesquisa exige, portanto, que o pesquisador se situe nesse processo, analisando criticamente o estado do conhecimento em sua área de interesse (ALVES, 1992, p.54).

O estado de conhecimento, portanto, supõe um estudo descritivo e analítico que objetiva a sistematização da produção bibliográfica numa determinada área do conhecimento (ROMANOWSKI; ENS, 2006).

A importância desta sistematização se justifica pela ausência de um estudo inventariante sobre a jornada de trabalho docente e pelo fato de que a perspectiva descritiva das pesquisas sobre a temática traz à luz aspectos a serem considerados nas investigações sobre trabalho

\footnotetext{
${ }^{4}$ O projeto, com vigência para o período 2016-2018, é financiado pelo Fundo de Apoio à Pesquisa da Universidade a qual os autores estão vinculados.
}

Periódico Horizontes - USF - Itatiba, SP-Brasil - e019012 
docente, formação de professores e políticas educacionais, entre outras.

Para a sistematização do estado de conhecimento sobre a jornada de trabalho docente foram consultadas dissertações, teses e artigos científicos publicados e apresentados em dois eventos da área de Educação.

\section{O processo de seleção e análise das pesquisas sobre jornada de trabalho docente}

O levantamento exploratório inicial das pesquisas que abordam a jornada de trabalho docente permitiu-nos identificar a existência de poucas produções dedicadas de forma mais central à análise da temática, não sendo necessário, inclusive, delimitar o período de análise.

O estudo mais antigo sobre a temática data de 2001 e é o único trabalho dentre os 27 analisados que é anterior a 2008. Os demais se concentram entre 2008 e 2016. Isso, provavelmente, pode ter relação com a aprovação da Lei n. 11.738 , de 2008 , que instituiu o Piso Salarial Profissional Nacional (BRASIL, 2008) que, por sua vez, colocou em pauta a discussão sobre os salários e as jornadas de trabalho docentes.

Em todas as buscas selecionamos apenas os trabalhos que tratam da jornada de trabalho docente no ensino fundamental e médio das redes públicas. Por adotarmos esse critério de seleção, desconsideramos os trabalhos que abordavam a jornada de trabalho docente na Educação Infantil, Educação Superior, Educação Especial, Educação de Jovens e Adultos, Educação a Distância e, também, aqueles que tratavam de experiências da rede privada de ensino, das escolas integrais ou de tempo integral e, por fim, os que se referiam a aspectos muito específicos de redes municipais. Entendemos que a jornada de trabalho docente nesses casos ganharia contornos muito específicos que dificultariam nossas conclusões.

As teses e dissertações foram consultadas no Banco de Teses e Dissertações da Coordenação de Aperfeiçoamento do Pessoal de Nível Superior (Capes) e na Biblioteca Digital Brasileira de Teses e Dissertações (BDTD). Na busca foram usados os descritores "jornada de trabalho docente" e "jornada de trabalho do professor". No Banco de Teses e Dissertações da Capes, a busca simples desses descritores apresentou mais de 900 mil resultados. No entanto, a

$$
\text { Periódico Horizontes - USF - Itatiba, SP-Brasil - e019012 }
$$


busca exata dessas expressões identificou 11 trabalhos. Desses, valendo-nos do critério de seleção descrito anteriormente, selecionamos 5 trabalhos. Na BDTD, a busca exata desses descritores resultou em 5 trabalhos dos quais 2 atendiam aos critérios de seleção adotados. Porém, ambos os trabalhos já haviam sido localizados no Banco de Teses e Dissertações da Capes. Diferentemente do banco da Capes, na BDTD a busca simples dos descritores mostrou-se mais viável, resultando em 129 resultados dos quais, após a leitura dos títulos e, em alguns casos, dos resumos, identificamos 7 trabalhos que satisfaziam aos critérios de seleção estabelecidos (um desses trabalhos já havia sido selecionado no Banco da Capes).

Os artigos científicos publicados em periódicos foram obtidos junto ao Scientific Electronic Library On-Line (Scielo). Nessa base, as buscas com as expressões "jornada de trabalho docente" e "jornada de trabalho do professor" resultaram em um único trabalho que foi selecionado para análise. Em buscas combinadas com as expressões "jornada", "trabalho" e "educação" foi possível obter 53 resultados dos quais selecionamos 5 adequados aos nossos critérios.

Os trabalhos apresentados em eventos foram levantados junto aos anais das reuniões da Associação Nacional de Pesquisa e Pós-Graduação em Educação (Anped) e dos seminários internacionais da Rede Latino-americana de Estudos sobre Trabalho Docente (REDE ESTRADO). As buscas foram realizadas na homepage da Anped utilizando os anais das reuniões que estão disponíveis online, ou seja, de 2000 (23ạ Reunião) até 2015 (37ạ Reunião), nos grupos de trabalho (GTs) Estado e Política Educacional (GT 5) e, também, Trabalho e Educação (GT 9), tendo sido selecionados 4 trabalhos para análise. Os anais dos seminários da REDE ESTRADO foram consultados por meio de seus CD-ROMs e, também, por meio de sua homepage. Conseguimos acesso aos anais dos seminários de 2006, 2008, 2010, 2012, 2014 e 2016 de onde selecionamos 7 trabalhos para análise.

Ao todo, foram selecionados 27 estudos, sendo 6 teses de doutorado (4 em Educação, uma em Engenharia de Produção e uma em História), 5 dissertações de mestrado (3 em Educação, uma em Processos Socioeducativos e Práticas Escolares e uma em Direito), 5 artigos publicados em periódicos da área da Educação e 11 trabalhos apresentados em anais, sendo 4 nas Reuniões Anuais da Anped e 7 nos Seminários Internacionais da REDE ESTRADO.

$$
\text { Periódico Horizontes - USF - Itatiba, SP-Brasil - e019012 }
$$


Cabe destacar que as pesquisas de mestrado e doutorado não estão concentradas em nenhum programa de pós-graduação específico. Muito embora o maior número de pesquisas tenha sido defendido em programas de Educação (7), há uma grande representatividade de instituições: Unicamp (2), USP (1), Unesp (1), UNIFESP (1), UFSM (1) e UFRGS (1). Os demais trabalhos foram desenvolvidos na UFSCar, UFRN, UJSJ e UFGD.

Apenas 10 dos estudos selecionados tinham a jornada de trabalho docente como uma temática principal, os demais tratavam centralmente de outros temas como os relacionados às condições de trabalho, salários, carreira e valorização docente. Considerando, entretanto, que esses temas estão diretamente vinculados à temática da jornada de trabalho docente, esses estudos também receberam nossa atenção.

Quadro 1. Teses selecionadas

\begin{tabular}{|c|c|c|c|c|c|}
\hline & TIPO & AUTOR(ES) & TÍTULO & ANO & ORIGEM \\
\hline 1 & Tese & $\begin{array}{l}\text { CAÇÃO, Maria } \\
\text { Izaura }\end{array}$ & $\begin{array}{l}\text { Jornada de Trabalho Docente: } \\
\text { delineamento histórico da } \\
\text { organização do trabalho do } \\
\text { magistério público paulista }\end{array}$ & 2001 & $\begin{array}{l}\text { Programa de Pós-Graduação } \\
\text { em Educação - Faculdade de } \\
\text { Educação (UNICAMP) }\end{array}$ \\
\hline 2 & Tese & $\begin{array}{l}\text { FARIA, } \\
\text { Graciela } \\
\text { Santujá Soares }\end{array}$ & $\begin{array}{l}\text { Organização do trabalho do } \\
\text { professor: jornada, contrato e } \\
\text { conflitos trabalho-família }\end{array}$ & 2010 & $\begin{array}{l}\text { Programa de Pós-Graduação } \\
\text { em Engenharia de Produção } \\
\text { - Centro de Ciências Exatas e } \\
\text { de Tecnologia (UFSCAR) }\end{array}$ \\
\hline 3 & Tese & $\begin{array}{l}\text { BARBOSA, } \\
\text { Andreza }\end{array}$ & $\begin{array}{l}\text { Os salários dos professores } \\
\text { brasileiros: implicações para o } \\
\text { trabalho docente }\end{array}$ & 2011 & $\begin{array}{l}\text { Programa de Pós-Graduação } \\
\text { em Educação Escolar - } \\
\text { Faculdade de Ciências e } \\
\text { Letras (UNESP) }\end{array}$ \\
\hline 4 & Tese & $\begin{array}{l}\text { RIBEIRO, } \\
\text { Josete Maria } \\
\text { Cangussú }\end{array}$ & $\begin{array}{l}\text { A jornada de trabalho dos } \\
\text { professores da escola pública em } \\
\text { contexto de políticas de } \\
\text { valorização docente e qualidade } \\
\text { da educação }\end{array}$ & 2014 & $\begin{array}{l}\text { Programa de Pós-Graduação } \\
\text { em Educação - Faculdade de } \\
\text { Educação (UFRGS) }\end{array}$ \\
\hline 5 & Tese & $\begin{array}{l}\text { SAGRILLO, } \\
\text { Daniele } \\
\text { Rorato }\end{array}$ & $\begin{array}{l}\text { O tempo de trabalho e o tempo } \\
\text { "livre" dos professores municipais } \\
\text { de Santa Maria/RS }\end{array}$ & 2015 & $\begin{array}{l}\text { Programa de Pós-Graduação } \\
\text { em Educação - Centro de } \\
\text { Educação (UFSM) }\end{array}$ \\
\hline 6 & Tese & $\begin{array}{l}\text { OLIVEIRA, } \\
\text { Mariana } \\
\text { Esteves de }\end{array}$ & $\begin{array}{l}\text { "Professor, você trabalha ou só dá } \\
\text { aula?": O fazer-se docente entre } \\
\text { história, trabalho e precarização } \\
\text { na SEE-SP }\end{array}$ & 2016 & $\begin{array}{l}\text { Programa de Pós-Graduação } \\
\text { em História - Faculdade de } \\
\text { Ciências Humanas (UFGD) }\end{array}$ \\
\hline
\end{tabular}

Fonte: Organização das autoras.

Periódico Horizontes - USF - Itatiba, SP-Brasil - e019012 
Quadro 2. Dissertações selecionadas

\begin{tabular}{|l|l|l|l|l|l|}
\hline 7 & Dissertação & $\begin{array}{l}\text { ALVARENGA, } \\
\text { Carolina Faria }\end{array}$ & $\begin{array}{l}\text { Relações de gênero e } \\
\text { trabalho docente: jornadas e } \\
\text { ritmos no cotidiano de } \\
\text { professores e professoras }\end{array}$ & 2008 & $\begin{array}{l}\text { Programa de Pós- } \\
\text { Graduação em Educação } \\
\text { - Faculdade de Educação } \\
\text { (USP) }\end{array}$ \\
\hline 8 & Dissertação & $\begin{array}{l}\text { CARNEIRO, } \\
\text { Flávio Henrique } \\
\text { Rodrigues }\end{array}$ & $\begin{array}{l}\text { O piso salarial nacional: A } \\
\text { valorização do professor na } \\
\text { constituição de 1988 }\end{array}$ & 2012 & $\begin{array}{l}\text { Programa de Pós- } \\
\text { Graduação em Direito - } \\
\text { Centro de Ciências } \\
\text { Sociais Aplicadas (UFRN) }\end{array}$ \\
\hline 9 & Dissertação & $\begin{array}{l}\text { MAGALHÃES, } \\
\text { Jaqueline } \\
\text { Gomes }\end{array}$ & $\begin{array}{l}\text { Conversas com professoras: } \\
\text { compreendendo como são } \\
\text { os usos dos tempos da } \\
\text { jornada de trabalho fora da } \\
\text { sala de aula no município de } \\
\text { Juiz de Fora/ MG }\end{array}$ & 2015 & $\begin{array}{l}\text { Programa de Pós- } \\
\text { Graduação em Processos } \\
\text { Socioeducativos e } \\
\text { Práticas Escolares - } \\
\text { Departamento de } \\
\text { Educação (UFSJ) }\end{array}$ \\
\hline 10 & Dissertação & $\begin{array}{l}\text { THOMAZINI, } \\
\text { Leandro }\end{array}$ & $\begin{array}{l}\text { Carreira e vencimento de } \\
\text { professores da educação } \\
\text { básica no estado de São } \\
\text { Paulo }\end{array}$ & 2016 & $\begin{array}{l}\text { Programa de Pós- } \\
\text { Graduação em Educação } \\
\text { - Escola de Filosofia, } \\
\text { Letras e Ciências } \\
\text { Humanas } \\
\text { UNIFESP }\end{array}$ \\
\hline 11 & Dissertação & $\begin{array}{l}\text { OLIVEIRA, } \\
\text { Marcela } \\
\text { Pergolizzi } \\
\text { Moraes de }\end{array}$ & $\begin{array}{l}\text { Jornada de trabalho e } \\
\text { remuneração de } \\
\text { professores: um estudo } \\
\text { sobre a vigência da Lei do } \\
\text { Piso Salarial na RMC }\end{array}$ & 2016 & $\begin{array}{l}\text { Programa de Pós- } \\
\text { Graduação em Educação } \\
\text { - Faculdade de Educação } \\
\text { (UNICAMP) }\end{array}$ \\
\hline
\end{tabular}

Fonte: Organização das autoras.

Quadro 3. Artigos de periódicos selecionados

\begin{tabular}{|c|c|c|c|c|c|}
\hline & TIPO & AUTOR(ES) & TÍTULO & ANO & ORIGEM \\
\hline 12 & $\begin{array}{l}\text { Artigo de } \\
\text { periódico }\end{array}$ & $\begin{array}{l}\text { ZIBETTI, Marli Lúcia } \\
\text { Tonatto } \\
\text { PEREIRA, Sidnéia } \\
\text { Ribeiro }\end{array}$ & $\begin{array}{l}\text { Mulheres e professoras: } \\
\text { repercussões da dupla } \\
\text { jornada nas condições de vida } \\
\text { e no trabalho docente }\end{array}$ & 2010 & Educar em Revista \\
\hline 13 & $\begin{array}{l}\text { Artigo de } \\
\text { periódico }\end{array}$ & $\begin{array}{l}\text { COSTA, Gilvan Luiz } \\
\text { Machado }\end{array}$ & $\begin{array}{l}\text { O ensino médio no Brasil: } \\
\text { desafios à matrícula e ao } \\
\text { trabalho docente }\end{array}$ & 2013 & $\begin{array}{l}\text { Revista Brasileira } \\
\text { de Estudos } \\
\text { Pedagógicos }\end{array}$ \\
\hline 14 & $\begin{array}{l}\text { Artigo de } \\
\text { periódico }\end{array}$ & $\begin{array}{l}\text { ARELARO, Lisete } \\
\text { Regina Gomes } \\
\text { JACOMINI, Márcia } \\
\text { Aparecida } \\
\text { SOUZA, Nilson Alves } \\
\text { SANTOS, Kátia }\end{array}$ & $\begin{array}{l}\text { Condições do trabalho } \\
\text { docente: uma análise da } \\
\text { carreira na rede municipal de } \\
\text { ensino de São Paulo }\end{array}$ & 2014 & $\begin{array}{l}\text { Revista Brasileira } \\
\text { de Estudos } \\
\text { Pedagógicos }\end{array}$ \\
\hline
\end{tabular}

Periódico Horizontes - USF - Itatiba, SP-Brasil - e019012 


\section{HSE HORIZON TES}

\begin{tabular}{|l|l|l|l|l|l|}
\hline & & Aparecida & & & \\
\hline 15 & $\begin{array}{l}\text { Artigo de } \\
\text { periódico }\end{array}$ & $\begin{array}{l}\text { CAMARGO, Rubens } \\
\text { Barbosa } \\
\text { MINHOTO, Maria } \\
\text { Angélica Pedra } \\
\text { JACOMINI, Márcia } \\
\text { Aparecida }\end{array}$ & $\begin{array}{l}\text { Carreira e remuneração do } \\
\text { magistério no município de } \\
\text { São Paulo: análise legislativa } \\
\text { em perspectiva histórica }\end{array}$ & 2014 & $\begin{array}{l}\text { Educação e } \\
\text { Sociedade }\end{array}$ \\
\hline 16 & $\begin{array}{l}\text { Artigo de } \\
\text { periódico } \\
\text { AparecinI, Márcia } \\
\text { PENNA, Marieta } \\
\text { Gouvêa de Oliveira }\end{array}$ & $\begin{array}{l}\text { Carreira docente e } \\
\text { valorização do magistério: } \\
\text { condições de trabalho e } \\
\text { desenvolvimento profissional }\end{array}$ & 2016 & Pro-posições \\
\hline
\end{tabular}

Fonte: Organização das autoras.

Quadro 4. Trabalhos publicados em anais de eventos selecionados

\begin{tabular}{|c|c|c|c|c|c|}
\hline & TIPO & AUTOR(ES) & TÍTULO & ANO & ORIGEM \\
\hline 17 & $\begin{array}{l}\text { Trabalho } \\
\text { Anais } \\
\text { Anped }\end{array}$ & $\begin{array}{l}\text { ALVES, Thiago; } \\
\text { PINTO, José } \\
\text { Marcelino Rezende }\end{array}$ & $\begin{array}{l}\text { Análise das características do } \\
\text { trabalho e da remuneração } \\
\text { docente no Brasil a partir das } \\
\text { bases de dados demográficas e } \\
\text { educacionais }\end{array}$ & 2011 & $\begin{array}{l}\text { 34a Reunião } \\
\text { Anual da Anped }\end{array}$ \\
\hline 18 & $\begin{array}{l}\text { Trabalho } \\
\text { Anais } \\
\text { Anped }\end{array}$ & BARBOSA, Andreza & $\begin{array}{l}\text { As implicações dos baixos } \\
\text { salários para o trabalho } \\
\text { docente no Brasil }\end{array}$ & 2012 & $\begin{array}{l}\text { 35a Reunião } \\
\text { Anual da Anped }\end{array}$ \\
\hline 19 & $\begin{array}{l}\text { Trabalho } \\
\text { Anais } \\
\text { Anped }\end{array}$ & $\begin{array}{l}\text { BRITO, Vera Lúcia } \\
\text { Ferreira Alves de }\end{array}$ & $\begin{array}{l}\text { A reforma da gestão pública e a } \\
\text { remuneração docente }\end{array}$ & 2015 & $\begin{array}{l}\text { 37ạ Reunião } \\
\text { Anual da Anped }\end{array}$ \\
\hline 20 & $\begin{array}{l}\text { Trabalho } \\
\text { Anais } \\
\text { Anped }\end{array}$ & $\begin{array}{l}\text { JACOMINI, Márcia } \\
\text { Aparecida; } \\
\text { CAMARGO, Rubens } \\
\text { Barbosa; } \\
\text { ALVES, Thiago }\end{array}$ & $\begin{array}{l}\text { Plano nacional de educação e } \\
\text { remuneração docente: desafios } \\
\text { para o monitoramento da } \\
\text { valorização profissional no } \\
\text { contexto da meta } 17\end{array}$ & 2015 & $\begin{array}{l}\text { 37ạ Reunião } \\
\text { Anual da Anped }\end{array}$ \\
\hline 21 & $\begin{array}{l}\text { Trabalho } \\
\text { Anais Rede } \\
\text { Estrado }\end{array}$ & $\begin{array}{l}\text { CAMARGO, Rubens } \\
\text { Barbosa; } \\
\text { GIL, Juca; } \\
\text { GOUVEIA, Andréa } \\
\text { Barbosa; } \\
\text { MINHOTTO, Maria } \\
\text { Angélica Pedra. }\end{array}$ & $\begin{array}{l}\text { Remuneração docente no } \\
\text { Brasil: antecedentes do piso } \\
\text { salarial profissional nacional }\end{array}$ & 2010 & $\begin{array}{l}\text { VIII Seminário } \\
\text { Internacional da } \\
\text { Rede Estrado }\end{array}$ \\
\hline
\end{tabular}

Periódico Horizontes - USF - Itatiba, SP-Brasil - e019012 


\begin{tabular}{|c|c|c|c|c|c|}
\hline 22 & $\begin{array}{l}\text { Trabalho } \\
\text { Anais Rede } \\
\text { Estrado }\end{array}$ & $\begin{array}{l}\text { COSTA, Gilvan Luiz } \\
\text { Machado }\end{array}$ & $\begin{array}{l}\text { Trabalho docente no ensino } \\
\text { médio no Brasil }\end{array}$ & 2010 & $\begin{array}{l}\text { VIII Seminário } \\
\text { Internacional da } \\
\text { Rede Estrado }\end{array}$ \\
\hline 23 & $\begin{array}{l}\text { Trabalho } \\
\text { Anais Rede } \\
\text { Estrado }\end{array}$ & MENGER, Amanda & $\begin{array}{l}\text { Carreira Docente em Risco? A } \\
\text { percepção dos professores } \\
\text { sobre a (des) valorização da } \\
\text { profissão. }\end{array}$ & 2012 & $\begin{array}{l}\text { IX Seminário } \\
\text { Internacional da } \\
\text { Rede Estrado }\end{array}$ \\
\hline 24 & $\begin{array}{l}\text { Trabalho } \\
\text { Anais Rede } \\
\text { Estrado }\end{array}$ & BARBOSA, Andreza & $\begin{array}{l}\text { Características e } \\
\text { especificidades do trabalho } \\
\text { docente: considerações para o } \\
\text { estudo da jornada e dos } \\
\text { salários dos professores } \\
\text { brasileiros }\end{array}$ & 2012 & $\begin{array}{l}\text { IX Seminário } \\
\text { Internacional da } \\
\text { Rede Estrado }\end{array}$ \\
\hline 25 & $\begin{array}{l}\text { Trabalho } \\
\text { Anais Rede } \\
\text { Estrado }\end{array}$ & $\begin{array}{l}\text { CAMARGO, Rubens } \\
\text { Barbosa; } \\
\text { NASCIMENTO, Ana } \\
\text { Paula Santiago; } \\
\text { MEDINA, Renata } \\
\text { Rodrigues de } \\
\text { Amorim }\end{array}$ & $\begin{array}{l}\text { Formas de ingresso e } \\
\text { possibilidades de jornada de } \\
\text { trabalho no magistério público } \\
\text { estadual de São Paulo em 2010: } \\
\text { descrição e análises } \\
\text { preliminares }\end{array}$ & 2014 & $\begin{array}{l}\text { X Seminário } \\
\text { Internacional da } \\
\text { Rede Estrado }\end{array}$ \\
\hline 26 & $\begin{array}{l}\text { Trabalho } \\
\text { Anais Rede } \\
\text { Estrado }\end{array}$ & $\begin{array}{l}\text { JACOMINI, Márcia } \\
\text { Aparecida. } \\
\text { PENNA, Marieta } \\
\text { Gouvêa de Oliveira }\end{array}$ & $\begin{array}{l}\text { Valorização do magistério da } \\
\text { educação básica: um estudo } \\
\text { sobre planos de carreira }\end{array}$ & 2014 & $\begin{array}{l}\text { X Seminário } \\
\text { Internacional da } \\
\text { Rede Estrado }\end{array}$ \\
\hline 27 & $\begin{array}{l}\text { Trabalho } \\
\text { Anais Rede } \\
\text { Estrado }\end{array}$ & $\begin{array}{l}\text { OLIVEIRA, Cristiane } \\
\text { Brito; } \\
\text { SILVA, Fernanda } \\
\text { Aparecida Oliveira; } \\
\text { REZENDE, Valéria } \\
\text { Moreira }\end{array}$ & $\begin{array}{l}\text { A hipersolicitação do professor } \\
\text { e suas condições de trabalho } \\
\text { no comprometimento da saúde } \\
\text { física e psíquica }\end{array}$ & 2016 & $\begin{array}{l}\text { XI Seminário } \\
\text { Internacional da } \\
\text { Rede Estrado }\end{array}$ \\
\hline
\end{tabular}

Fonte: Organização das autoras.

Após a leitura e análise dos trabalhos selecionados com base na análise de conteúdo (BARDIN, 2002) foi possível organizar a contribuição desses estudos para a compreensão da jornada de trabalho docente em quatro eixos temáticos: jornada de trabalho e salários docentes; jornada de trabalho e a especificidade do trabalho docente; jornada de trabalho e gênero; e jornada de trabalho e legislação.

Convém lembrar que a sistematização da discussão realizada por esses estudos nesses quatro eixos é didática, tendo em vista que eles estão diretamente relacionados entre si e, por isso, muitas vezes um mesmo estudo traz considerações sobre a temática de mais de um eixo.

Periódico Horizontes - USF - Itatiba, SP-Brasil - e019012 
De qualquer forma, ainda que a separação das discussões nesses eixos possa parecer artificial, acreditamos que ela é necessária para sistematizar as contribuições trazidas por essas pesquisas para a compreensão da jornada de trabalho docente. Essa sistematização pode ajudar outros pesquisadores interessados em aspectos específicos da discussão proposta.

\section{Jornada de trabalho e salários docentes}

A maior parte dos estudos relaciona, de forma direta, a jornada de trabalho dos professores à remuneração recebida por eles (ALVARENGA, 2008; CAMARGO et al, 2010; COSTA, 2013, 2010; FARIA, 2010; ALVES; PINTO, 2011; BARBOSA, 2012a, 2012b, 2011; MENGER, 2012; CARNEIRO, 2012; RIBEIRO, 2014; ARELARO et al, 2014; JACOMINI; ALVES; CAMARGO, 2015; JACOMINI; PENNA, 2016; OLIVEIRA, 2016b). Isso se justifica pelo fato de que na maioria dos sistemas de ensino os professores são remunerados em função do número de horas-aula que ministram, o que faz com que a remuneração dependa da jornada assumida pelo docente. Assim, se a remuneração é proporcional ao número de horas trabalhadas, a principal forma de compensar os baixos ganhos é ampliando a jornada de trabalho.

Jacomini, Alves e Camargo (2015) e Oliveira (2016b) apontam que a democratização do acesso à educação pública teve implicações para as condições de trabalho docente: o aumento de matrículas levou ao aumento do número de professores, à redução dos salários e, consequentemente, à ampliação da jornada. Em que pese a importância da democratização do acesso à educação não se pode ignorar que ela não veio acompanhada de políticas de financiamento. Pelo contrário, para atender um maior número de crianças e jovens as condições de trabalho dos profissionais da educação foram ainda mais sacrificadas.

Camargo et al (2010) fazem uma análise dos aspectos salariais nos períodos de 1997 até 2007 dos professores da educação básica de vários estados e apontam a vinculação entre salários e jornada de trabalho, destacando as diferenças observadas na composição das jornadas de trabalho nos diferentes estados: 
É de se observar que a menor jornada de trabalho informada era a do RS com 16 horas semanais e a maior era a correspondente a 40 horas semanais realizadas (e informadas) nas redes estaduais do AP (2007), CE (2007), DF (1997), PB (1997), RN (1997), RO (1997), RR (1997), SC (1997 e 2007), SE (1997 e 2007), SP (1997) e TO (1997 e 2007). (CAMARGO et al, 2010, p. 7).

Alves e Pinto (2011), ao analisar a remuneração docente com base em dados da Pesquisa Nacional por Amostra de Domicílios (PNAD) de 2009, apontam que mais de $50 \%$ dos professores que participaram da pesquisa declararam trabalhar 40 horas semanais ou mais. Essas informações coincidem com os dados levantados por Barbosa (2012a, p.9) que indicam um crescimento do número de horas semanais trabalhadas pelos professores, sobretudo nos anos finais do ensino fundamental e ensino médio: “[...] é considerável a porcentagem de professores que declarou trabalhar 40 horas ou mais por semana: $51 \%$ nos anos iniciais do Ensino Fundamental e 57\% nos anos finais do Ensino Fundamental e no Ensino Médio".

Para além da simples ampliação do número de aulas assumidas dentro de uma mesma rede de ensino ou dentro de um mesmo cargo, os baixos salários têm reflexos na configuração das jornadas de trabalho docente à medida que levam, em muitos casos, ao acúmulo de cargos, muitas vezes, em redes de ensino diferentes. É comum que os docentes, mesmo sendo efetivos, trabalhem na rede estadual ou municipal, ou ainda, na rede privada. O acúmulo de cargos em diferentes sistemas de ensino, além de fazer com que o professor tenha que se ajustar a diferentes realidades, envolve o tempo (e o dinheiro) gastos com o deslocamento entre as diferentes escolas, fato que se torna ainda mais grave quando se trata de escolas em municípios diferentes (SAGRILLO, 2015; MAGALHÃES, 2015; OLIVEIRA, 2016a).

Na dissertação de Alvarenga (2008), onde a autora analisa os ritmos e jornadas dos docentes de uma escola pública do município de São Paulo, em coleta de dados feita com 16 professores a partir de questionários, é possível notar que grande parte deles $(68,8 \%)$ trabalha tanto na rede municipal quanto na estadual. $\mathrm{O}$ acúmulo de cargos também acontece em busca de melhores salários e é possível pela falta de professores que há nas redes, permitindo que um mesmo professor possa dar aulas em diversas escolas, principalmente no ensino médio (COSTA, 2010). 
Também há casos de professores que, além da dupla jornada, assumem outras funções além da docência para compensar os baixos salários (BARBOSA, 2011; OLIVEIRA, 2016b), intensificando sua jornada de trabalho e comprometendo o tempo dedicado ao planejamento de aulas, correção de atividades e preparação de aulas (BARBOSA, 2011, 2012a, 2012b; CARNEIRO, 2012; COSTA, 2013), o que, por usa vez, também faz com que o nível de estresse e de doenças aumente (FARIA, 2010).

As pesquisas analisadas ainda apontam que a relação entre remuneração e jornada de trabalho docente assume contornos ainda mais críticos se considerarmos as diferentes formas de contratação de professores que costumam coexistir nas diferentes redes de ensino, como é o caso dos professores efetivos e temporários.

No caso específico da rede pública estadual paulista, Faria (2010) destaca que existem diversos tipos de contrato de trabalho docentes nessa rede e, consequentemente, as jornadas de trabalho também variam bastante. Em sua pesquisa, aplicou questionário com 95 professores da rede pública de ensino de São Paulo e verificou que 33,7\% desses docentes eram Admitidos em Caráter Temporário (ACT). Ainda foi possível observar que os professores com contrato em caráter temporário ficavam com as jornadas menores dentro da rede pública paulista, enquanto os professores efetivos trabalhavam em jornadas maiores. Isso acontece porque os professores efetivos têm suas aulas atribuídas antes dos temporários que, por sua vez, acabam ficando com as aulas remanescentes. Assim, para conseguir um número de aulas que possa garantir minimamente sua subsistência, esses professores assumem o máximo possível de aulas na rede o que, frequentemente, significa assumir aulas em várias escolas diferentes uma vez que essas aulas são as que restam depois da atribuição feita aos professores efetivos.

Dados mais recentes levantados por Camargo, Nascimento e Medina (2014) apontam que $50 \%$ dos professores da rede pública estadual paulista são efetivos, enquanto o restante se encontra "estabilizado", com contrato de caráter temporário ou são eventuais. Os professores temporários têm pouco ou nada de garantias trabalhistas o que, por sua vez, contribui para intensificar as jornadas de trabalho em diversas escolas, para tentar compensar a situação de instabilidade gerada pela contratação temporária (FARIA 2010; CAMARGO; NASCIMENTO; 
MEDINA, 2014).

Lennert (2011), discutindo as condições de trabalho do professor de sociologia, ainda sinaliza que os professores efetivos, pela garantia que têm de seus salários base, atuam nas escolas centrais, enquanto isso, os temporários e eventuais, para obter uma renda melhor, procuram os adicionais das escolas de periferia com periculosidade e adicionais noturnos.

Os estudos analisados ainda apontam que, na maioria das vezes, somente os professores efetivos têm acesso às diferentes formas de progressão na carreira previstas pelos sistemas de ensino, o que faria com que os professores temporários recebessem menos (por não conseguirem progredir na carreira) e, por isso, ampliassem sua jornada de trabalho (LENNERT, 2011; JACOMINI; PENNA, 2014).

Talvez seja por esse conjunto de fatores que, na pesquisa de Menger (2012), a relação entre salários e jornada de trabalho docente apareça dentro da temática da valorização dos professores. Os professores que participaram de sua pesquisa sinalizaram que a valorização da profissão docente estaria relacionada com o aumento dos salários, o reconhecimento da sociedade e a redução da jornada de trabalho.

Assim, de acordo com as pesquisas consideradas, baixos salários podem levar à ampliação da jornada de trabalho e, se considerarmos a especificidade do trabalho docente, isso pode ter consequências para a qualidade do trabalho desempenhado pelo professor, o que pode ser agravado ainda pela questão de gênero que envolve a docência, como será discutido nos dois eixos seguintes.

\section{Jornada de trabalho e a especificidade do trabalho docente}

Outra questão também discutida de forma recorrente nas pesquisas analisadas diz respeito à necessidade de se analisar a jornada de trabalho dos professores tendo em vista as especificidades do trabalho docente.

Como já foi destacado, o trabalho do professor não se limita a ministrar aulas. Seu trabalho envolve o planejamento, as avaliações, o cumprimento de tarefas burocráticas, os registros, a

$$
\text { Periódico Horizontes - USF - Itatiba, SP-Brasil - e019012 }
$$


participação em reuniões etc. realizados fora do horário de aula e, muitas vezes, fora do horário contratual de trabalho visto que o período de trabalho dos professores na escola é insuficiente para dar conta de todas as demandas da docência (OLIVEIRA, 2016a; SAGRILLO, 2015).

Dada essa especificidade, Jacomini e Penna (2014) destacam a necessidade de adequar a remuneração docente à importância dos professores na sociedade e, também, para melhorar a atratividade na carreira e "[...] permitir uma jornada de trabalho compatível com a especificidade do trabalho docente" (p.11).

Sobre a carga horária que deveria ser destinada às atividades extraclasse, as autoras destacam que ministrar aulas em mais de uma escola e em redes diferentes sem um número adequado de horas destinado ao trabalho de apoio à docência requer que o professor trabalhe em casa para preparar aulas, corrigir trabalhos, provas etc., comprometendo, assim, sua qualidade de vida. Dessa forma, além de sinalizar para a especificidade da docência no que diz respeito às atividades extraclasse, as pesquisas também destacam a importância da adequação das jornadas à função desempenhada pelos professores, ressaltando que jornadas excessivas podem comprometer o trabalho docente e, consequentemente, a qualidade da educação.

Isso ocorre porque o prolongamento das jornadas traz consequências para o trabalho docente como comprometimento do tempo destinado às atividades extraclasse (BARBOSA, 2011), adoecimento do professor (ZIBETTI; PEREIRA, 2010; JACOMINI; PENNA, 2016; OLIVEIRA; SILVA; REZENDE, 2016) e, consequentemente, prejudicam a qualidade da educação (ARELARO et al, 2014, JACOMINI; PENNA, 2016).

Jacomini e Penna (2016) discutem os resultados de pesquisa que abordou a remuneração de professores em 12 estado brasileiros e afirmam que a prática do acúmulo de cargos eleva a possibilidade de adoecimento do professor e contribui para a queda do seu desempenho em função do excesso de trabalho. Dessa forma, prejudica-se a qualidade do ensino por conta do excesso de licenças médicas e, também, porque reduz-se a qualidade das aulas devido ao cansaço do professor.

Ao analisarem as condições de trabalho de professoras do ensino fundamental, considerando as dificuldades e pressões sofridas e seus efeitos sobre as condições físicas e

$$
\text { Periódico Horizontes - USF - Itatiba, SP-Brasil - e019012 }
$$


psicológicas, Oliveira, Silva e Rezende (2016) apontam que as professoras mencionaram sentir cansaço constante em função das atividades que a função docente requer. Além das atividades que desempenham em sala de aula, essas professoras relataram ser necessário levar trabalho para casa, configurando uma rotina de trabalho exaustiva que tem levado ao surgimento de problemas de saúde.

Assumir um grande número aulas implica ainda ter que dar conta do ensino e da aprendizagem de um grande número de alunos. Faria (2010) observou que, dos professores que participaram de sua pesquisa, 25,26\% têm de 6 a 10 turmas de alunos, sendo também que a média observada de número de alunos por professor foi de 404,7. Essa situação, evidentemente, tem desdobramentos para a qualidade do trabalho do professor.

Ribeiro (2014) analisa as jornadas de trabalho dos professores de escolas públicas e destaca que a quantidade e a qualidade da jornada de trabalho docente estão diretamente relacionadas à qualidade da educação, uma vez que a jornada de trabalho seria condição para que os professores pudessem repensar a organização do seu trabalho. Em decorrência disso, segundo a autora, as condições de trabalho docente como jornadas e remuneração não podem ser consideradas como bem exclusivo da docência, uma vez que, em função das características do trabalho docente, afetam diretamente os alunos. Assim, a valorização do professor seria não apenas um direito do professor, mas também direito do aluno. Ribeiro (2014) ainda sinaliza que a implementação de jornadas de trabalho coerentes com as características do ofício docente e a busca da qualidade da educação passa "[...] por políticas de financiamento robustas" (p.84).

De forma semelhante, Arelaro et al (2014), assim como Alves e Pinto (2011) enfatizam ser necessário remuneração adequada e jornadas de trabalho que se adequem à especificidade da docência e contemplem hora de trabalho extraclasse a ser cumprida na escola e estimulem a dedicação exclusiva à docência e, preferencialmente, em uma única escola, para que seja possível dar um salto de qualidade na educação.

Nesse sentido, Jacomini, Alves e Camargo (2015) afirmam que qualquer comparação entre a jornada de trabalho do professor e a jornada de trabalho de outras profissões que se pretenda justa deveria considerar a especificidade do trabalho docente de exigir tempo para

$$
\text { Periódico Horizontes - USF - Itatiba, SP-Brasil - e019012 }
$$


além do tempo em sala de aula para ser realizada.

\section{Jornada de trabalho e gênero}

Também foi possível observar nas pesquisas que foram alvo de nossa atenção a vinculação da discussão da jornada de trabalho dos professores à questão de gênero. Como a docência é uma profissão predominantemente feminina e, como em nossa sociedade as mulheres ainda ficam responsáveis pelo trabalho doméstico e o cuidado com os filhos, alguns autores, como Barbosa (2012b), apontam para a impossibilidade de descartar a questão de gênero ao estudarmos a jornada de trabalho docente, afinal, na maioria das vezes, à jornada de trabalho da professora se soma a jornada de trabalho doméstico, como é apontado pela pesquisa de Alvarenga (2008), Zibetti e Pereira (2010), Magalhães (2015), Sagrillo (2015) e Oliveira (2016b).

A pesquisa de Faria (2010) destaca, com base na Relação Anual de Informações Sociais (RAIS), que as mulheres são a maioria na profissão docente no Brasil. Em 2005, 70,3\% dos professores eram mulheres no Brasil, enquanto no estado de São Paulo 71,5 eram mulheres.

Alvarenga (2008), que se dedicou a estudar as relações de gênero no trabalho docente, destaca que a presença das mulheres é maior na educação infantil e nos anos iniciais do ensino fundamental. Isso, por sua vez, tem desdobramentos na remuneração recebida pelos professores, pois os salários docentes nos anos finais do ensino fundamental e no ensino médio costumam ser maiores que os dos níveis iniciais da educação básica. Ou seja, as professoras, além de acumularem a jornada de trabalho docente com o trabalho doméstico ainda ganham menos que os homens. Apesar disso, a jornada de trabalho das professoras e dos professores são igualmente intensificadas dentro da escola e, também, na realização do trabalho extraclasse.

Em uma pesquisa que discute as condições de vida e trabalho de mulheres professoras da educação infantil e das séries iniciais do ensino fundamental em municípios do estado de Rondônia, Zibetti e Pereira (2010) apontam para a necessidade de as políticas educacionais levarem em consideração a predominância de mulheres nesses níveis de ensino. Essas autoras lembram que a docência com crianças pequenas pode ser muito desgastante, uma vez que é

$$
\text { Periódico Horizontes - USF - Itatiba, SP-Brasil - e019012 }
$$


necessário atenção e paciência constante e, também resistência física.

Segundo essas autoras, a discussão sobre o tempo necessário para o planejamento e elaboração de materiais a serem utilizados nas aulas dentro da jornada de trabalho se torna ainda mais relevante quando se considera a questão de gênero uma vez que, na ausência ou insuficiência desses horários, as professoras acabam levando trabalho para casa que, por sua vez, se soma ao trabalho doméstico e tem desdobramentos negativos para a qualidade de vida das professoras e, também, para o trabalho desenvolvido por elas (ZIBETTI; PEREIRA, 2010). Para além da sobrecarga de trabalho oriunda da docência e da vida doméstica, as professoras que foram sujeitos dessa pesquisa ainda frequentavam cursos de formação no período noturno o que contribuía para reduzir ainda mais o tempo livre.

Dessa forma, parece que a questão da jornada de trabalho docente reflete, como afirmam Zibetti e Pereira (2010) aspectos culturais que são reproduzidos nas relações familiares, visto que as mulheres continuam assumindo as demandas que assumiam antes de entrarem no mercado de trabalho, mas também tem estreita relação com a baixa remuneração recebida na docência, "[...] pois enquanto outros/as profissionais mais bem remunerados/as encontram tempo livre para a família e o lazer por meio da contratação de mão de obra doméstica, as professoras não têm condições de fazer o mesmo" (ZIBETTI; PEREIRA, 2010, p.270).

Dessa forma, as pesquisas analisadas aqui apontam que se as jornadas de trabalho docente já são, em geral, extensas e intensas, em se tratando do trabalho especificamente desempenhado pelas professoras, observa-se ainda maior intensificação e isso, sem dúvida, precisa ser considerado ao analisarmos as jornadas de trabalho docente e, também na formulação de políticas educacionais para "[...] garantir igualdade de oportunidades e de condições de vida para os professores e as professoras [...]" (ALVARENGA, 2008, p. 160).

\section{Jornada de trabalho e legislação}

Esse eixo assume um caráter um pouco diferente dos anteriores à medida que apresenta as respostas da legislação para as questões apontadas nos demais eixos. É que como a jornada

Periódico Horizontes - USF - Itatiba, SP-Brasil - e019012 
de trabalho dos professores é regulamentada pela legislação federal e pela legislação dos diferentes entes federados, a maioria dos estudos analisados dedica-se, pelo menos em parte deles, à discussão da jornada de trabalho docente com base nessas leis (CAÇÃO, 2001; CARNEIRO, 2012; BARBOSA, 2012b; CAMARGO, NASCIMENTO; MEDINA, 2014; JACOMINI; PENNA, 2014; ARELARO et al, 2014; BRITO, 2015; THOMAZINI, 2016; OLIVEIRA, 2016a). Embora isso possa parecer óbvio e possível para muitos dos temas da área da educação, a questão da relação entre jornada de trabalho e a legislação é relevante tendo em vista os avanços e retrocessos observados nos últimos anos.

A legislação que regulamenta a profissão docente pode ser considerada um indicativo de quanto esse profissional é valorizado pelo Estado, pelos governos e pela própria sociedade. Sobre isso, Lennert (2011) destaca que as mudanças na legislação costumam refletir em todos os campos que cercam a docência, sobretudo na qualidade do trabalho do professor e, consequentemente, do ensino.

Adrião e Camargo (2007), ao estudarem os elementos relacionados à gestão democrática na legislação brasileira, destacam que as leis são sínteses dos embates e disputas de diferentes grupos e que, embora a garantia legal de algo que está sendo reivindicado seja importante, a simples presença desse elemento no texto da lei não garante a sua efetivação: "Eis parte da ambiguidade que acompanha as conquistas no plano da lei: as contradições entre o proposto e o implementado" (ADRIÃO; CAMARGO, 2007, p. 64).

A produção acadêmica sobre a jornada de trabalho docente traduz de forma significativa essas contradições entre o proposto e o implementado. Nesse sentido, a tese de Cação (2001), ao apresentar um histórico das jornadas de trabalho dos professores paulistas, destaca a luta das entidades representativas da categoria, principalmente do Sindicato dos Professores do Ensino Oficial do Estado de São Paulo (APEOESP), pela reformulação do Estatuto do Magistério paulista com vistas a obter melhores condições de trabalho no interior das escolas e, dentre essas condições, a jornada de trabalho figurava como uma das demandas.

Cação (2001) destaca, porém, que o que sempre moveu a ação dos docentes paulistas foi a questão salarial, e as demais demandas (como a jornada de trabalho) ficavam, muitas vezes, 
em segundo plano. Para ilustrar essa afirmação, a autora menciona o fato de a categoria ter aceitado a ampliação de sua jornada de trabalho para compensar os baixos salários. No final dos anos 70, havia três possíveis jornadas de trabalho: de 20, 30 ou 40 horas com um percentual muito pequeno de horas destinado às atividades extraclasse (10\% apenas) e a possibilidade de ampliação dessas jornadas com carga de trabalho suplementar.

Há que se ressaltar que a APEOESP, na década de 80, reivindicava uma jornada única de trabalho docente composta de 30 horas semanais, das quais 20 se dariam em sala de aula e as 10 restantes caracterizariam horas atividades. O entendimento da entidade era o de que jornadas extensas eram desgastantes e não contribuíam para a qualidade do ensino (CAÇÃO, 2001).

Outro aspecto frequentemente observado nas pesquisas analisadas no que diz respeito à legislação relativa à jornada de trabalho dos professores no Brasil diz respeito à Lei n. 11.738 de 16 de julho de 2008, que instituiu o Piso Salarial Profissional Nacional. Essa lei, inicialmente, previa a remuneração de $\mathrm{R} \$ 950$ por uma jornada de trabalho de, no máximo, 40 horas semanais para os profissionais com formação em nível médio (Curso Normal) e, também, previa que, no máximo, 2/3 dessa jornada fosse destinado às atividades em sala de aula. (BRASIL, 2008).

Essa lei teve sua constitucionalidade questionada por alguns governadores brasileiros, mas foi julgada constitucional pelo Supremo Tribunal Federal (STF), estando em vigor atualmente. O valor estabelecido pela Lei do Piso é corrigido anualmente de acordo com a variação do valor aluno-ano do Fundo de Manutenção e Desenvolvimento da Educação Básica e de Valorização do

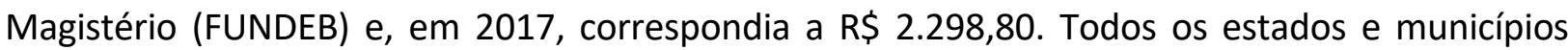
devem cumprir essa lei, ou seja, nenhum professor brasileiro deve receber menos que o valor instituído ou ter jornada com composição diferente da estabelecida por essa lei.

É curioso observar que as pesquisas localizadas sobre a temática da jornada de trabalho docente concentram-se no período posterior à aprovação da Lei do Piso, sobretudo, posteriormente ao julgamento de sua constitucionalidade, quando deveria, portanto, ser implementada pelos sistemas de ensino. Assim, muitas das pesquisas analisadas (CARNEIRO, 2012; CAMARGO; NASCIMENTO; MEDINA, 2014; ARELARO et al, 2014; BRITO, 2015; THOMAZINI, 2016; OLIVEIRA, 2016a) dedicam-se, em algum momento, a verificar o cumprimento ou não

$$
\text { Periódico Horizontes - USF - Itatiba, SP-Brasil - e019012 }
$$


dessa lei por parte do sistema de ensino que analisa.

A Lei do Piso representou um avanço significativo na legislação nacional com vistas à valorização do magistério e tem sido alvo de discussão de vários estudos. Exemplo disso é a dissertação de mestrado de Carneiro (2012) que, da área do Direito, vem abordar "[...] os mecanismos jurídicos usados pelo Legislativo e pelo Executivo para concretizar o princípio constitucional do piso salarial do professor, como uma estratégia de valorização profissional dessa categoria" (CARNEIRO, 2012, p.9).

Segundo Carneiro (2012) apesar da Lei do Piso determinar que 1/3 da jornada de trabalho docente deve ser destinado às atividades extraclasses (como a correção de atividades, preparação de aulas e provas, reuniões pedagógicas e estudos), quando da realização de sua pesquisa, apenas 15 estados cumpriam essa determinação, o que, segundo o autor, estaria relacionado à falta de Planos Estaduais de Educação e, também, à insuficiência de orçamento, pois adequar a jornada a essa nova deliberação implicaria na necessidade de contratação de mais professores.

De forma semelhante, Brito (2015), ao analisar a reforma da gestão pública e as políticas de ajuste fiscal considerando seus efeitos sobre o financiamento da educação e, principalmente para a implantação da Lei do Piso, destaca que em 2014 a lei ainda não era cumprida por 7 estados brasileiros e outros 14 estados não a cumpriam integralmente por não respeitar o disposto quanto à composição da jornada de trabalho do professor. Em 2014, apenas Acre, Ceará, Distrito Federal, Pernambuco e Tocantins cumpriam a lei na totalidade (BRITO, 2015).

O estado de São Paulo, mesmo sendo o mais rico da federação, descumpre a lei do piso quanto à jornada. Sobre isso, Camargo, Nascimento e Medina (2014) destacam que os docentes da rede pública estadual paulista trabalham mais que $2 / 3$ de sua jornada com alunos.

Essa constatação é reforçada pela pesquisa de Thomazini (2016) que, analisando os estatutos e planos de carreira do magistério da rede estadual de São Paulo e de quatro municípios paulistas, observou que os municípios analisados não cumprem a Lei do Piso integralmente em função de não terem adequado suas jornadas de trabalho ao que é estabelecido pela lei. O mesmo, segundo esse autor, aconteceria no estado de São Paulo que

$$
\text { Periódico Horizontes - USF - Itatiba, SP-Brasil - e019012 }
$$


teria realizado uma manobra matemática para tentar se adequar à lei, sem que isso representasse avanço no que diz respeito à composição da jornada de trabalho dos professores paulistas.

Arelaro et al (2014), ao analisarem as formas de ingresso, a composição da jornada de trabalho, a progressão na carreira e a composição da remuneração dos professores da rede municipal de São Paulo, apontam a existência de 5 diferentes jornadas de trabalho docente nessa rede, sendo que em apenas uma destas cumpre-se o percentual de 1/3 para a realização de atividades extraclasse como é estabelecido pela Lei do Piso.

Oliveira (2016a) analisando as condições de trabalho dos professores da região metropolitana de Campinas constatou que, dos 20 municípios que compõem essa região, 11 cumprem a lei do Piso no que diz respeito à jornada de trabalho, 5 cumprem a lei apenas em algumas jornadas, 3 já aprovaram legislação que altera e adequa a jornada à lei, mas ainda não implementaram e 1 município não cumpre a lei e não alterou sua legislação. Também constata diferenças nos processos pelos quais esses municípios foram tentando se adequar à lei.

Outro instrumento legal que também figura nas pesquisas analisadas (BARBOSA, 2012b; JACOMINI; PENNA, 2014) é a Resolução CNE/CEB n. 2 de 2009 que fixa as diretrizes para a elaboração dos planos de carreira do magistério. Sobre isso, Jacomini e Penna (2014), apontam que a jornada de trabalho é fundamental para que haja condições de trabalho adequadas e que, reforçando essa compreensão, a Resolução n. 2 de 2009 propõe como princípio a jornada de tempo integral ( 40 horas) a ser cumprida preferencialmente em uma única escola.

Apesar disso, Arelaro et al (2014) sinalizam que a rede municipal de São Paulo permite o acúmulo de cargos tornando possível assumir uma jornada de até $70 \mathrm{~h} /$ semanais. Segundo esses autores, esse acúmulo tem sido realizado, como já apontado, para compensar os baixos salários e, contraditoriamente, professores e sindicatos têm defendido o direito ao acúmulo. Admitindose os efeitos nocivos que jornadas tão extensas possam ter sobre a qualidade do trabalho docente, Ribeiro (2014) afirma que deveriam existir mecanismos legais que pudessem coibir jornadas excessivas.

Tendo em vista as considerações feitas pelos trabalhos analisados quanto a esse eixo -

$$
\text { Periódico Horizontes - USF - Itatiba, SP-Brasil - e019012 }
$$


jornada de trabalho e legislação - fica evidente que as pesquisas têm dedicado atenção significativa à legislação em função dessas determinarem mudanças efetivas na jornada de trabalho dos professores, embora, como mencionado anteriormente, muitas vezes, não seja efetivado o que é disposto na lei. As pesquisas indicam ainda que, nos últimos anos, foram obtidos alguns avanços nesse campo o que, sem dúvida, é fruto das lutas da categoria docente. Porém, como síntese de um processo de disputa de interesses, em alguns momentos, é possível observar que a legislação é alterada na contramão das necessidades e reivindicações da docência.

Sobre isso, Ribeiro (2014) aponta que embora tenhamos avançado nos últimos anos no sentido de tentar normatizar alguns princípios para a valorização docente e para a melhoria das condições de trabalho, não existem mecanismos legais que vinculem o tempo de trabalho do professor à identidade profissional e à natureza do trabalho docente de forma a atender plenamente as necessidades da jornada de trabalho docente tendo em vista o que foi discutido nos eixos anteriores.

\section{Considerações finais}

A temática da jornada de trabalho dos professores, como se pode depreender da análise descritiva deste estudo, tem sido foco de interesse de pesquisas, sobretudo a partir da aprovação da Lei do Piso (Lei n. 11.638/2008). Essa lei colocou em pauta essa discussão ao retomar a importância de condições de trabalho adequadas (dentre elas salários e jornadas) para o desenvolvimento do trabalho docente.

Barbosa (2011) sintetiza a lógica que organiza as jornadas de trabalho dos professores e impacta o trabalho docente: para compensar os baixos salários e obter melhores rendimentos, os professores têm sido levados a buscar jornadas de trabalho mais intensas, assumindo mais aulas e, muitas vezes, trabalhando em mais de uma escola e em mais de um período ao dia. Uma jornada de trabalho extensa contribui para o aumento da rotatividade e itinerância dos professores nas escolas e compromete a qualidade do trabalho, pois prejudica a dedicação às atividades extraclasse e seu investimento no próprio aprimoramento profissional. Além disso, a

$$
\text { Periódico Horizontes - USF - Itatiba, SP-Brasil - e019012 }
$$


intensificação da jornada de trabalho potencializa o adoecimento e absenteísmo desses profissionais.

Essa lógica ganha contornos mais sérios à medida que as pesquisas analisadas também apontam para a necessidade de se considerar as especificidades do trabalho docente na formulação das jornadas de trabalho dos professores. Como esse trabalho não ocorre somente em sala de aula e, portanto, envolve atividades que, necessariamente, precisam ser realizadas fora do tempo cumprido com os alunos (preparar aulas, corrigir provas e atividades etc.) é fundamental que a composição das jornadas de trabalho contemple tempo suficiente para o cumprimento dessas atividades. Caso contrário, a qualidade do trabalho do professor pode ficar extremamente prejudicada.

Ora, se as características da docência implicam na necessidade de trabalhar para além do tempo de sala de aula e se não existe tempo suficiente para dar conta dessas atividades dentro da jornada de trabalho, os professores acabam por levar trabalho para realizar em casa. Se considerarmos que a docência é uma profissão ocupada predominantemente por mulheres, isso se torna ainda mais exigente, pois as atividades extraclasse se somam às tarefas domésticas e o cuidado com os filhos.

Por fim, as pesquisas apontam que a legislação brasileira apresentou recentemente alguns avanços na tentativa de contemplar as questões relacionadas à jornada de trabalho docente, embora não dê conta de atender plenamente as características específicas da docência e os sistemas de ensino nem sempre cumpram o disposto nessa legislação.

Tendo em vista os resultados das pesquisas aqui discutidas fica evidente que a jornada de trabalho docente é uma das condições de trabalho que mais pode influenciar a qualidade do trabalho desenvolvido pelos professores. Sendo assim, parece ser fundamental que os resultados dessas pesquisas sejam considerados pelos estudos que se dediquem a analisar temas relacionados ao trabalho docente, como formação de professores ou práticas pedagógicas. Desconsiderar as condições efetivas que os professores têm para desenvolver seu trabalho pode implicar na acentuação da responsabilização dos professores pelos resultados obtidos no processo educacional. Ainda que os professores tenham papel central nesse processo, não

$$
\text { Periódico Horizontes - USF - Itatiba, SP-Brasil - e019012 }
$$


podemos perder de vista que, para a realização de um trabalho de qualidade, é necessário garantir condições mínimas para que esse trabalho seja desenvolvido. As pesquisas analisadas aqui sinalizam que a jornada de trabalho faz parte desse conjunto de condições.

\section{Referências}

ADRIÃO, T.; CAMARGO, R. B. A gestão democrática na Constituição Federal de 1988. In: OLIVEIRA, R. P.; ADRIÃO, T. (Org.). Gestão, financiamento e direito à educação: análise da Constituição Federal e da LDB. 3. ed. São Paulo: Xamã, 2007. p. 63-71.

ALVARENGA, C. F. Relações de gênero e trabalho docente: jornadas e ritmos no cotidiano de professores e professoras. 2008. 174 f. Dissertação (Mestrado em Educação) - Universidade de São Paulo, São Paulo, 2008.

ALVES, A. J. A "revisão da bibliografia" em teses e dissertações: meus tipos inesquecíveis. Cadernos de Pesquisa, São Paulo, n.81, p.53-60, mai. 1992.

ALVES, T.; PINTO, J. M. R. Análise das características do trabalho e da remuneração docente no Brasil a partir das bases de dados demográficas e educacionais. In: REUNIÃO ANUAL DA ASSOCIAÇÃO NACIONAL DE PÓS-GRADUAÇÃO E PESQUISA EM EDUCAÇÃO - ANPED, 34., 2011, Natal. Anais [...] Natal: Anped, 2011. p.1-24.

ARELARO, L. R. G. et al. Condições do trabalho docente: uma análise da carreira na rede municipal de ensino de São Paulo. Revista Brasileira de Estudos Pedagógicos, Brasília, v.95, n.234, p.197-217, jan./abr. 2014.

BARBOSA, A. Os salários dos professores brasileiros: implicações para o trabalho docente. 2011. 210 f. Tese (Doutorado em Educação Escolar) - Universidade Estadual Paulista Júlio de Mesquita Filho, Araraquara, 2011.

BARBOSA, A. As implicações dos baixos salários para o trabalho docente no Brasil. In: REUNIÃO ANUAL DA ASSOCIAÇÃO NACIONAL DE PÓS-GRADUAÇÃO E PESQUISA EM EDUCAÇÃO - ANPED, 35., 2012, Porto de Galinhas. Anais [...] Porto de Galinhas: Anped, 2012a. p.1-18.

BARBOSA, A. Características e especificidades do trabalho docente: Considerações para o estudo da jornada e dos salários dos professores brasileiros. In: SEMINÁRIO DA REDE LATINOAMERICANA DE ESTUDOS SOBRE TRABALHO DOCENTE- REDE ESTRADO, 9. 2012, Santiago. Anais [...] Santiago: Rede Estrado, 2012b. 1 CD-ROM. p.1-13.

$$
\text { Periódico Horizontes - USF - Itatiba, SP-Brasil - e019012 }
$$


BARDIN, L. Análise de conteúdo. 1ae ed. Lisboa: Ed. 70, 2002.

BRASIL. Lei n. 11.738 de 16 de julho de 2008. Regulamenta a alínea "e" do inciso III do caput do art. 60 do Ato das Disposições Constitucionais Transitórias, para instituir o piso salarial profissional nacional para os profissionais do magistério público da educação básica. Disponível em: http://www.planalto.gov.br/ccivil/_Ato2007-2010/2008/Lei/L11738.htm. Acesso em 07 ago. 2017.

BRITO, V. L. F. A. A reforma da gestão pública e a remuneração docente. In: REUNIÃO ANUAL DA ASSOCIAÇÃO NACIONAL DE PÓS-GRADUAÇÃO E PESQUISA EM EDUCAÇÃO - ANPED, 37, 2015, Florianópolis. Anais [...] Florianópolis: Anped, 2015. p.1-37.

CAÇÃO, M. I. Jornada de Trabalho Docente: delineamento histórico da organização do trabalho do magistério público paulista. 2001. 218 f. Tese (Doutorado em Educação) - Universidade Estadual de Campinas, Campinas, 2001.

CAMARGO, R. B. et al. Remuneração docente no Brasil: antecedentes do piso salarial profissional nacional. In: SEMINÁRIO DA REDE LATINO-AMERICANA DE ESTUDOS SOBRE TRABALHO DOCENTE- REDE ESTRADO, 8. 2010, Lima. Anais [...] Lima: Rede Estrado, 2010. 1 CD-ROM. p.1-13.

CAMARGO, R. B.; NASCIMENTO, A. P. S.; MEDINA, R. R. A. Formas de ingresso e possibilidades de jornada de trabalho no magistério público estadual de São Paulo em 2010: descrição e análises preliminares. In: SEMINÁRIO DA REDE LATINO-AMERICANA DE ESTUDOS SOBRE TRABALHO DOCENTE- REDE ESTRADO, 10. 2014, Salvador. Anais [...] Salvador: Rede Estrado, 2014. 1 CD-ROM. p.1-15.

CARNEIRO, F. H. R. O piso salarial nacional: a valorização do professor na constituição de 1988. 2012. 217 f. Dissertação (Mestrado em Direito) - Universidade Federal do Rio Grande do Norte, Natal, 2012.

COSTA, G. L. M. Trabalho docente no ensino médio no Brasil. In: SEMINÁRIO DA REDE LATINOAMERICANA DE ESTUDOS SOBRE TRABALHO DOCENTE - REDE ESTRADO, 8. 2010, Lima. Anais [...] Lima: Rede Estrado, 2010. 1 CD-ROM. p.1-12.

COSTA, G. L. M. O ensino médio no Brasil: desafios à matrícula e ao trabalho docente. Revista Brasileira de Estudos Pedagógicos, Brasília, v.94, n.236, p.185-210, abr. 2013.

FARIA, G. S. S. Organização do trabalho do professor: jornada, contrato e conflitos trabalhofamília. 2010. 173 f. Tese (Doutorado em Ciências Exatas e da Terra) - Universidade Federal de São Carlos, São Paulo, 2010.

$$
\text { Periódico Horizontes - USF - Itatiba, SP-Brasil - e019012 }
$$


FERREIRA, N. S. A. As pesquisas denominadas "estado da arte". Educação e Sociedade, Campinas, v.23, n.79, p.257-272, ago. 2002.

FRANCHI, E. P. A insatisfação dos professores: conseqüências para a profissionalização. In. FRANCHI, E. P. (Org.). A causa dos professores. Campinas: Papirus, 1995. p. 17-90.

JACOMINI, M. A.; ALVES, T.; CARMARGO, R. B. Plano Nacional de Educação e remuneração docente: desafios para o monitoramento da valorização profissional no contexto da meta 17. In: REUNIÃO ANUAL DA ASSOCIAÇÃO NACIONAL DE PÓS-GRADUAÇÃO E PESQUISA EM EDUCAÇÃO - ANPED, 37. 2015, Florianópolis. Anais [...] Florianópolis: Anped, 2015. p.1-23.

JACOMINI, M. A.; PENNA, M. G. O. Valorização do magistério da educação básica: um estudo sobre planos de carreira. In: SEMINÁRIO DA REDE LATINO-AMERICANA DE ESTUDOS SOBRE TRABALHO DOCENTE- REDE ESTRADO, 10. 2014, Salvador. Anais [...] Salvador: Rede Estrado, 2014. 1 CD-ROM. p.1-16.

JACOMINI, M. A.; PENNA, M. G. O. Carreira docente e valorização do magistério: condições de trabalho e desenvolvimento profissional. Pro-Posições, Campinas, v.27, n.2(80), p.177-202, maio/ago. 2016.

LENNERT, A. L. Condições de Trabalho do Professor de Sociologia. Caderno Cedes, Campinas, v.31, n.85, p.383-403, dez. 2011.

MAGALHÃES, J. G. Conversas com professoras: compreendendo como são os usos dos tempos da jornada de trabalho fora da sala de aula no município de Juiz de Fora/ MG. 2015. 94 f. Dissertação (Mestrado em Processos Socioeducativos e Práticas Escolares) - Universidade Federal de São João del-Rei, São João del-Rei, 2015.

MENGER, A. Carreira Docente em Risco? A percepção dos professores sobre a (des) valorização da profissão. In: SEMINÁRIO DA REDE LATINO-AMERICANA DE ESTUDOS SOBRE TRABALHO DOCENTE- REDE ESTRADO, 9. 2012, Santiago. Anais [...] Santiago: Rede Estrado, 2012. 1 CDROM. p.1-17.

MOROSINI, M. C.; FERNANDES, C. M. B. Estado do conhecimento: conceitos, finalidades e interlocuções. Educação por Escrito, Porto Alegre, v.5, n.2, p.154-164, jul./dez. 2014.

OLIVEIRA, C. B.; SILVA, F. A. O; REZENDE, V. M. A hipersolicitação do professor e suas condições de trabalho no comprometimento da saúde física e psíquica. In: SEMINÁRIO DA REDE LATINOAMERICANA DE ESTUDOS SOBRE TRABALHO DOCENTE- REDE ESTRADO, 11. 2016, Cidade do México. Anais [...] Cidade do México: Rede Estrado, 2016. p.1-18.

OLIVEIRA, D. A. Trabalho docente. In. OLIVEIRA, D. A.; DUARTE, A. M. C.; VIEIRA, L. M. F. (Org.). Periódico Horizontes - USF - Itatiba, SP-Brasil - e019012 
Dicionário: trabalho, profissão e condição docente. Belo Horizonte: UFMG / Faculdade de Educação, 2010. 1 CD-ROM. Não paginado.

OLIVEIRA, M. P. M. Jornada de trabalho e remuneração de professores: um estudo sobre a vigência da lei do piso salarial na RMC. 2016a. 143 f. Dissertação (Mestrado em Educação) Universidade Estadual de Campinas, Campinas, 2016a.

OLIVEIRA, M. E. "Professor, você trabalha ou só dá aula?": o fazer-se docente entre história, trabalho e precarização na SEE-SP. 2016b. 267 f. Tese (Doutorado em História) - Universidade Federal da Grande Dourados, Dourados, 2016b.

RIBEIRO, J. M. C. A jornada de trabalho dos professores da escola pública em contexto de políticas de valorização docente e qualidade da educação. 2014. 264 f. Tese. (Doutorado em Educação) - Universidade Federal do Rio Grande do Sul, Porto Alegre, 2014.

ROMANOWSKI, J. M.; ENS, R. T. As pesquisas denominadas do tipo "estado da arte" em educação. Diálogo Educacional, Curitiba, v.6, n.19, p.37-50, set./dez. 2006.

SAGRILLO, D. R. O tempo de trabalho e o tempo "livre" dos professores municipais de Santa Maria/RS. 2015. 242 f. Tese. (Doutorado em Educação) - Universidade Federal de Santa Maria, Santa Maria, 2015.

SOUZA, A. N. Condições de trabalho na carreira docente: comparação Brasil-França. In: SEMINÁRIO DA REDE LATINO-AMERICANA DE ESTUDOS SOBRE TRABALHO DOCENTE- REDE ESTRADO, 7. 2008, Buenos Aires. Anais [...] Buenos Aires: Rede Estrado, 2008. 1 CD-ROM. p.014.

THOMAZINI, L. Carreira e vencimento de professores da educação básica no estado de São Paulo. 2016. 246 f. Dissertação. (Mestrado em Educação) - Universidade Federal de São Paulo, Guarulhos, 2016.

VOSGERAU, D. S. R; ROMANOWSKI, J. P. Estudos de revisão: implicações conceituais e metodológicas. Revista Diálogo Educacional, Curitiba, v.14, n.41, p.165-189, jan./abr. 2014.

ZIBETTI, M. L. T; PEREIRA, S. R. Mulheres e professoras: repercussões da dupla jornada nas condições de vida e no trabalho docente. Educar em Revista, Curitiba, n.2, p. 259-276, 2010.

Recebido em novembro de 2017.

Aprovado em junho de 2018.

Periódico Horizontes - USF - Itatiba, SP-Brasil - e019012 